\title{
A MODIFIED METHOD OF VON MISES STRESS-BASED MWCM FOR FATIGUE-LIFE PREDICTION UNDER FULLY-REVERSED AXIAL-TORSION PROPORTIONAL LOADS
}

\author{
MODIFICIRANA METODA ZA NAPOVED DOBE TRAJANJA NA \\ OSNOVI VON MISESOVE NAPETOSTI-METODE MWCM V \\ POGOJIH POPOLNIH REVERZIBILNIH OSNO-ZVOJNIH \\ PROPORCIONALNIH OBREMENITEV
}

\author{
Bowen Liu, Xiangqiao Yan \\ Research Lab on Composite Materials, Harbin Institute of Technology, 150001, P.R.China \\ Prejem rokopisa - received: 2018-09-01; sprejem za objavo - accepted for publication: 2018-10-17
}

doi:10.17222/mit.2018.173

\begin{abstract}
In this paper, based on the Modified Wöhler Curve Method (MWCM), a novel multi-axial stress-invariant-based method is proposed. It has the ability to reduce the error produced by the deviation of the multi-axial parameter, which is an obvious influencing factor on the prediction accuracy. The new method introduces a ratio parameter to turn the von Mises stress into a new equivalent stress for fatigue assessments. An empirical hypothesis is taken as the starting point, and the iterative method is adopted to calculate the parameter more accurately. The present method was systematically validated with a large number of fatigue tests. It can be shown that, overall, the accuracy of the modified method has a certain degree of improvement compared to the original ones.

Keywords: multi-axial fatigue, fatigue life prediction, metallic materials
\end{abstract}

Avtorji opisujejo novo večosno napetostno invariantno metodo, ki temelji na modificirani Wöhlerjevi krivulji (MWCM; angl: Modified Wöhler Curve Method). Metoda omogoča zmanjšanje napake zaradi odstopanja večosnega parametra, ki očitno vpliva na natančnost napovedi. Nova metoda uvaja za oceno utrujanja parameter 1 , ki pretvarja von Misesovo napetost v novo ekvivalentno napetost. Kot izhodišče so vzeli empirično hipotezo in uporabili iterativno metodo za bolj natančen izračun parametra 1. Predstavljeno metodo so uspešno ovrednotili na velikem številu preizkusov utrujanja. Dokazali so, da je natančnost modificirane metode do določene mere boljša v primerjavi z izvorno metodo.

Ključne besede: večosno utrujanje, napoved dobe trajanja, kovinski materiali

\section{INTRODUCTION}

Fatigue is a common cause of failure in metallic components subjected to cyclic loadings. Plenty of attempts have been made to derive the fatigue criteria. Of particular note is the Modified Wöhler Curve Method (MWCM), recently proposed by Susmel et al. ${ }^{1}$ In contrast to previous methods, the MWCM does not focus on constructing the complex equivalent parameter quantifying the multi-axial fatigue damage, but still selects the classic shear-stress range and a modified form of the Wöhler equation. The significant innovation point of the MWCM is to obtain the corresponding multi-axial fatigue curve by interpolating those of axial and torsional loadings. However, the determination of the critical plane by calculating the maximum shear-stress range is sometimes extremely time consuming, thereby limiting the usefulness of the MWCM to address practical problems.

Based on the innovation point of the MWCM, several modified methods in terms of stress-invariant parameters

*Corresponding author e-mail yanxiangqiao406@163.com were developed to improve the computational efficiency, such as Cristofori et al., ${ }^{2}$ who presented a second invariant of the stress-deviator-based approach, and Sun et al., ${ }^{3}$ who devised an equivalent Lemaitre stress-based model for a multi-axial random fatigue evaluation. These methods prove that the choice of fatigue parameters and multi-axial parameters can be diverse. Moreover, for non-proportional cases, a general loading path can be transformed into a 5D Euclidean dimensional curve by using a deviatoric stress tensor. ${ }^{4}$ Meanwhile, plenty of convex enclosure models have been proposed to determine the ranges of the stress-invariant parameters in $5 \mathrm{D}$ space. $^{5}$

According to the characteristics of the interpolation method, the calculation error decreases with the reduction of the interpolation range. Turning to the methods derived from the MWCM, it can be concluded that the prediction accuracy increases with the decreasing distance between the two basic uniaxial (axial and torsion) curves. In this way, it can reduce the error produced by the deviation of the multi-axial parameter. To realize the above, a new method is presented in this article. In addition, it is worthwhile pointing out that the present study 
is only to discuss the fully-reversed axial-torsion proportional cases, because this loading type is the basis for the calibrations of other complex loads and it can reflect the multi-axial effect on fatigue life more accurately.

\section{THE MODIFIED METHOD OF VON MISES STRESS-BASED MWCM}

\subsection{Theoretical background of von Mises stress-based MWCM}

Derived from the MWCM, ${ }^{1}$ Cristofori et al. presented a modified approach in terms of the square root of the deviator second invariant. ${ }^{2}$ In the 5D Euclidean space, the invariant parameter can be calculated as $\sqrt{J_{2}}=\sqrt{s(t) \cdot s(t)}$, where the vector $s(t)=\left[s_{1}(t), s_{2}(t), s_{3}(t), s_{4}(t), s_{5}(t)\right]$ is defined by the following transformation rules:

$$
\begin{aligned}
& s_{1}(t)=\frac{\sqrt{3}}{2} \sigma_{x x}^{\prime}(t) ; \quad s_{2}(t)=\frac{1}{2}\left(\sigma_{y y}^{\prime}(t)-\sigma_{z z}^{\prime}(t)\right) \\
& s_{3}(t)=\tau_{x y}^{\prime}(t) ; \quad s_{4}(t)=\tau_{x z}^{\prime}(t) ; \quad s_{5}(t)=\tau_{y z}^{\prime}(t)
\end{aligned}
$$

Where $\sigma^{\prime}$ is the stress deviator. $\sigma^{\prime}=\sigma-\sigma_{\mathrm{H}} I$, where $\sigma$ is the whole stress tensor; $\sigma_{\mathrm{H}}$ is the hydrostatic stress (i.e., the first invariant of $\sigma$ ), and $I$ is the unit tensor. Under a fully reversed bending-torsion loading, the vector $s(t)$ has only two non-null components:

$$
\begin{aligned}
& s_{1}(t)=\frac{\sqrt{3}}{2} \sigma_{x x}(t) ; \quad s_{3}(t)=\tau_{x y}(t) \\
& s_{2}(t)=s_{4}(t)=s_{5}(t)=0
\end{aligned}
$$

Hence, the amplitude of the square root of the deviator second invariant becomes:

$$
\sqrt{J_{2, a}}=\frac{1}{\sqrt{3}} \sqrt{\sigma_{x x, a}^{2}+3 \tau_{x y, a}^{2}}
$$

A multi-axial parameter $\rho$ was proposed to better understand the degree of multi-axiality of the stress fields damaging the fatigue process zone: ${ }^{2}$

$$
\begin{gathered}
\rho=\sqrt{3} \frac{\sigma_{\mathrm{H}, \mathrm{ref}}}{\sqrt{J_{2, a}}} \\
\sigma_{\mathrm{H}, \mathrm{ref}}=\frac{\sigma_{x x, a}}{3}
\end{gathered}
$$

It is evident that for the axial and pure torsional fatigue conditions, the values of the multi-axial parameter $\rho$ are equal to 1 and 0 , respectively. In this loading case, the Cristofori method can be rewritten as:

$$
\lg \sigma_{\text {ea }}=A_{\rho} \lg N_{\mathrm{f}}+C_{\rho}
$$

Where $N_{\mathrm{f}}$ is the fatigue failure cycle and $\sigma_{\text {ea }}$ is the amplitude of the von Mises stress:

$$
\sigma_{\text {ea }}=\sqrt{\sigma_{x x, a}^{2}+3 \tau_{x y, a}^{2}}
$$

Where $A_{\rho}, C_{\rho}$ are the material parameters. As with the MWCM, ${ }^{1}$ they are determined by simple linear-interpolation laws: ${ }^{2}$

$$
\begin{aligned}
& A_{\rho}=A_{1} \cdot \rho+A_{0} \cdot(1-\rho) \\
& C_{\rho}=C_{1} \cdot \rho+C_{0} \cdot(1-\rho)
\end{aligned}
$$

Where $A_{1}, C_{1}$ and $A_{0}, C_{0}$ are the corresponding coefficients in the axial and torsional loadings. The multi-axial parameter $\rho$ can be simplified as:

$$
\rho=\frac{\sigma_{x x, a}}{\sigma_{e, a}}
$$

As shown in Figure 1, the method can fully take into account the multi-axiality effect by considering both the axial and torsional detrimental contributions to multiaxial fatigue damage.

\subsection{Introduction of the proposed modified method}

From the investigations of the MWCM it can be seen that the fitting precisions of both the two uniaxial fatigue curves and the multi-axial parameter $\rho$ impact on the multi-axial prediction accuracy. In particular, because of the complexity of the fatigue evolution, it is impossible to find an exact form of parameter $\rho$ to represent the multi-axiality degree of the stress fields for all materials. Thus, due to the deviation of the multi-axial parameter, the predicted curve obtained by Equation (8) of the assessed multi-axial case is different from the corresponding experimental curve, as shown in Figure 1.

A modified method is proposed in this section to solve the problem mentioned above. The two uniaxial fatigue curves are not parallel in general, so they will definitely intersect at one point, $O$. According to the hypothesis of the MWCM, it implies that the multi-axial fatigue curves would also pass through this point, theoretically.

Figure 1 shows that in the vicinity of the intersection point $\mathrm{O}$, the difference between the calculated life $\lg N_{\text {cal }}$ and the experimental life $\lg N_{\text {exp }}$ caused by the multiaxial parameter deviation is less than that away from the point $\mathrm{O}$. According to this characteristic, the modified

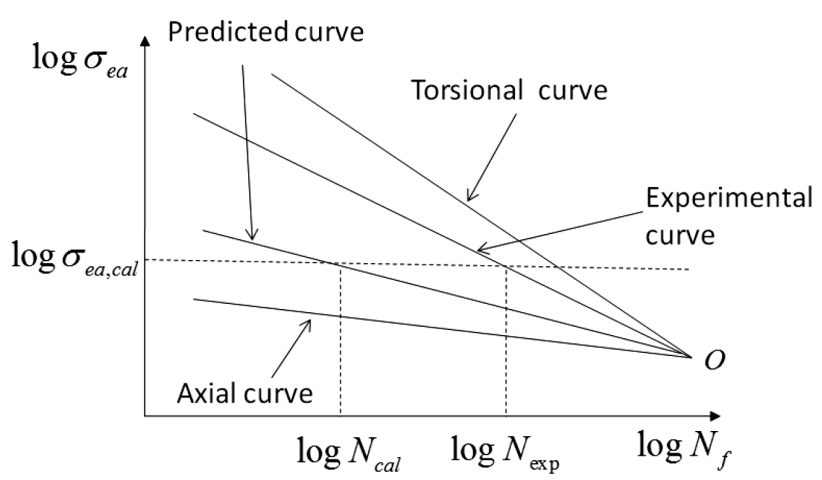

Figure 1: Modified Wöhler Curve diagram in terms of the von Mises stress-invariant-based approach 
method attempts to reduce this difference by approaching the intersection point to the coordinate region of the evaluated point. To make this attempt a reality, a ratio parameter $\lambda$ is introduced before the shear-stress components, which turns the von Mises stress into a new equivalent stress. The expression under axial-torsional loadings can be written as follows:

$$
\sigma_{\text {eq }}^{\prime}=\sqrt{\sigma_{x x}^{2}+3\left(\lambda t_{x y}\right)^{2}}
$$

The amplitude of the new equivalent stress is substituted into the axial and torsional forms of Equation (6), so that the corresponding equations can be obtained:

$$
\begin{aligned}
& \lg \left(\sigma_{\text {eq,a }}\right)=\lg \left(\sigma_{x x, \mathrm{a}}\right)=A_{1}^{\prime} \lg (N)+C_{1}^{\prime} \\
& \lg \left(\sigma_{\text {eq a }}^{\prime}\right)=\lg \left(\sqrt{3\left(\lambda t_{x y, a}\right)^{2}}\right)= \\
& =\lg \left(\sqrt{3\left(t_{x y, a}\right)^{2}}\right)+\lg (\lambda)=A_{1}^{\prime} \lg (N)+C_{0}^{\prime}
\end{aligned}
$$

Equation (11) is the same as the axial form of Equation (6). However, it can be determined from the comparison between Equation (12) and the torsional form of Equation (6), the slope coefficient, $A_{0}^{\prime}$ is the same as $A_{0}$, whereas the intercept coefficient $C_{0}$ increases $\lg (\lambda)$. Reflected in the double logarithmic coordinate, the position of the axial curve is unchanged, but the torsional fatigue curve moves $\lg (\lambda)$ along the coordinate axis in the $\mathrm{Y}$ direction. Substituting the modified equivalent stress amplitude into Equation (6), the multi-axial fatigue equation of the new method can be obtained:

$$
\lg \left(\sigma_{\mathrm{eq}, \mathrm{a}}^{\prime}\right)=\sqrt{\sigma_{\mathrm{xx}, \mathrm{a}}^{2}+3\left(\lambda t_{x y, a}\right)^{2}}=A_{1}^{\prime} \lg (N)+C_{0}^{\prime}
$$

For a certain bending-torsion proportional loading, there exists a loading ratio coefficient $k$ :

$$
k=\frac{\tau_{x y, a}}{\sigma_{x x, a}}
$$

The loading ratio coefficient $k$ is brought into Equation (13); it can be reformulated:

$$
\lg \left(\sigma_{\mathrm{xx}, \mathrm{a}} \sqrt{1+3 k^{2}} \frac{\sqrt{1+3 k^{2} \lambda^{2}}}{\sqrt{1+3 k^{2}}}\right)=A_{\rho}^{\prime} \lg (N)+C_{\rho}^{\prime}
$$

Equation (15) can be written in the form:

$$
\begin{aligned}
& \lg \left(\sigma_{\mathrm{xx}, \mathrm{a}} \sqrt{1+3 k^{2}}\right)=\lg \left(\sqrt{\sigma_{x x, a}^{2}+3 \tau_{x y}^{2}}\right)= \\
& =A_{\rho}^{\prime \prime} \lg (N)+C_{\rho}^{\prime \prime}
\end{aligned}
$$

where:

$$
A_{\rho}^{\prime \prime}=A_{\rho}^{\prime}, C_{\rho}^{\prime \prime}=C_{\rho}^{\prime}+\lg \left(\frac{\sqrt{1+3 k^{2} \lambda^{2}}}{\sqrt{1+3 k^{2}}}\right)
$$

It can be observed from the comparison between Equation (6) and Equation (17) that the slope is not changed, but the intercept moves $\lg \left(\sqrt{1+3 k^{2} \lambda^{2}} / \sqrt{1+3 k^{2}}\right)$ along the $\mathrm{Y}$ axis in the $\log -\log$ coordinate.

In addition, to make the proposed method correct, an empirical hypothesis is put forward here, i.e., the modified multi-axial experimental curves in terms of the new equivalent stress also pass through the intersection of the axial and modified torsional curves, as shown in Figure 2. The hypothesis will be verified in the next subsection in detail. As expressed by Equations (11), (12) and (16), the modified S-N curves are all parallel to those of the original von Mises method, and the distance between the two uniaxial curves at the nearby position of the evaluated point $O$ ' is reduced. Thus, the gap between the predicted life and the experimental life can be decreased, as shown in Figure 2.

Because the actual life of an evaluated point is impossible to know in advance, the iterative approach is adopted to determine the location of the intersection more accurately. In detail, the multi-axial fatigue life is first predicted by the von Mises stress-based method, so that a result can be obtained, $N_{0}$ Then taking this $N_{0}$ as the starting point, the corresponding vertical coordinates of the original axial and torsional cases can be calculated by substituting $N_{0}$ into the axial and torsional forms of Equation (6):

$$
\begin{aligned}
& y_{\sigma}=10^{A_{1}^{\prime} \lg (N)+C_{1}^{\prime}} \\
& y_{\tau}=10^{A_{0}^{\prime} \lg (N)+C_{0}^{\prime}}
\end{aligned}
$$

Based on Equations (18) and (19), the ratio parameter $\lambda$ of first step can be estimated:

$$
\tau=\frac{y_{\sigma}}{y_{\tau}}
$$

Subsequently, the new equivalent stress under the evaluated bending-torsion loading can be obtained by using the parameter $\lambda$ :

$$
\sigma_{\text {eq }}^{\prime}=\sqrt{\sigma_{x x}^{2}+3\left(\frac{y_{\sigma}}{y_{\tau}} \tau_{x y}\right)}
$$

Thus, a new prediction can be achieved with the modified method, $N_{1}$ Furthermore, the result can be updated once by taking $N_{1}$ as a restart point. The above iterative

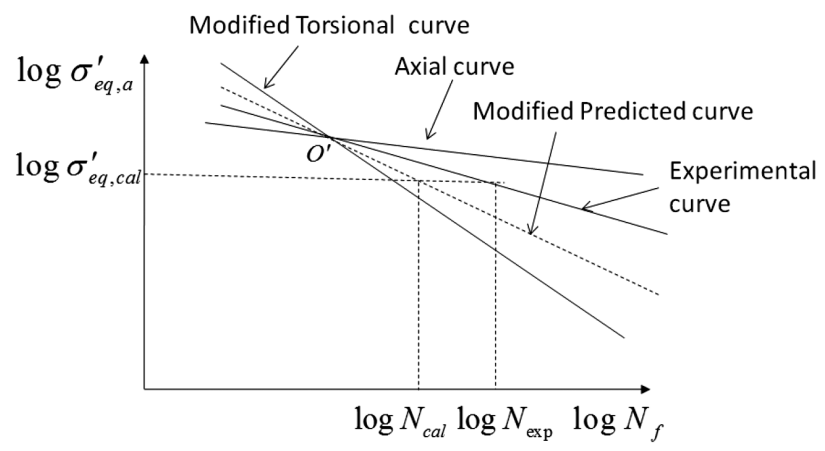

Figure 2: The multi-axial S-N curves of the modified method 
procedure can be repeated until a final convergence value is obtained.

In addition, it needs to ensured that the updated intersection is closer to the predicted experimental point than the previous one. This is because the core idea of the new method is to decrease the error by reducing the sensitivity of the multi-axial parameter. In other words, improve the accuracy by decreasing the range between the axial and torsional curves at the position of the evaluated point. Therefore, the following criterion is proposed to judge whether the range between the axial and torsional curves is reduced after the update:

$$
\begin{aligned}
& \left|y_{\tau}^{0}-y_{\sigma}^{0}\right| \geq\left|y_{\tau}^{1}-y_{\sigma}^{1}\right| \\
& \left|y_{\tau}^{0}-y_{\sigma}^{0}\right| \leq\left|y_{\tau}^{1}-y_{\sigma}^{1}\right|
\end{aligned}
$$

Where $y_{\sigma}^{0}$ and $y_{\sigma}^{1}$ are the axial vertical coordinates of the intersection points in the previous and updated steps, respectively, according to Equation(18); $y_{\tau}^{0}$ and $y_{\tau}^{1}$ are the corresponding torsional values calculated using Equation (19). If Equation (22) is tenable, it indicates that the interpolation interval between the axial and torsional curves at the position of the predicted point is reducing, i.e., the new intersection is closer to the actual experimental point than the previous one, and the iteration can be continued. Otherwise, if Equation (23) is satisfied, the update should be terminated.

\subsection{Experimental verification of the proposed empiri- cal hypothesis}

The proposed empirical hypothesis can be regarded as an extension of the elliptic quadrant criterion of Gough $^{6}$ (Equation (24)) from the fatigue limit to the finite life interval.

$$
\left(\frac{\sigma_{x y, a}}{\sigma_{0}}\right)^{2}+\left(\frac{\tau_{x y, a}}{\tau_{0}}\right)^{2}=1
$$

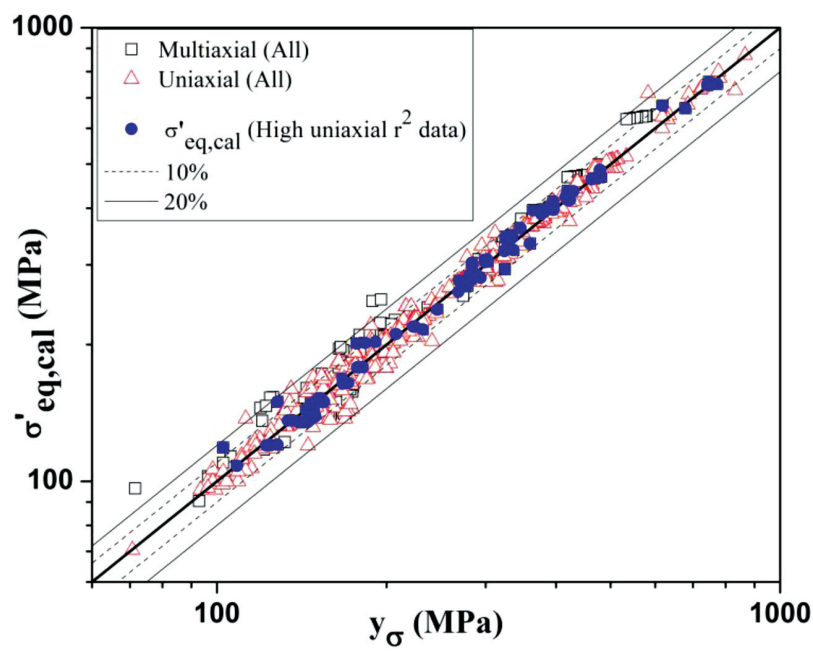

Figure 3: Comparisons of predicted results of the multi-axial data and the uniaxial data related to all the selected materials and those with a high uniaxial R-square
The assumption is verified by comparing the difference between the new equivalent stress, $\sigma_{\text {eq,cal, }}$, calculated with Equation (21) and the vertical coordinate of the intersection point, $y_{\sigma}$, calculated with Equation (18). In addition, it can be seen from Equation (20) that the parameter $\lambda$ is estimated with the parameters $y_{\sigma}$ and $y_{\tau}$, which are obtained from the two uniaxial S-N curves. Therefore, the accuracy of the comparison between

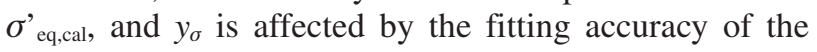
two uniaxial curves.

First, the prediction accuracy of the multi-axial data for all the selected materials ${ }^{7-9}$ ( 21 sets of materials with 226 multi-axial experimental points) is compared with that of the uniaxial data. Meanwhile, to quantify the accuracy degree, a relative error $E S$ is defined as follows:

$$
E S=\frac{\sigma_{e q, c a l}^{\prime}-y_{\sigma}}{y} \cdot 100 \%
$$

As can be seen in Figure 3, the accuracy of the points representing the multi-axial states is approximate to that of the uniaxial cases in general, with the vast majority of the relative error being within the range of $\pm 20 \%$. Numerically, $92.47 \%$ of the data fall within an error interval of $\pm 15 \%$, and $80.09 \%$ of the data fall within an error interval of $\pm 10 \%$, as shown in Figure 4 .

To reduce the influence caused by the fitting degree of the uniaxial curves, part of the data with the high $\mathrm{R}$-square of the uniaxial S-N curves is selected, and the corresponding specific values of the R-square are listed in Table 1. ${ }^{7-9}$ The comparisons between $\sigma^{\prime}$ eq,cal and $y_{\sigma}$ of the multi-axial data (113 multi-axial experimental points) are shown in Figures 3 and $\mathbf{4}$. The vast majority of the relative error is within the range of $\pm 10 \%$. Numerically, $96.46 \%$ of the data fall within an error of $\pm 10 \%$, and $85.84 \%$ of the data fall within an error interval of $\pm 5 \%$. This error is significantly lower than that of all the materials.

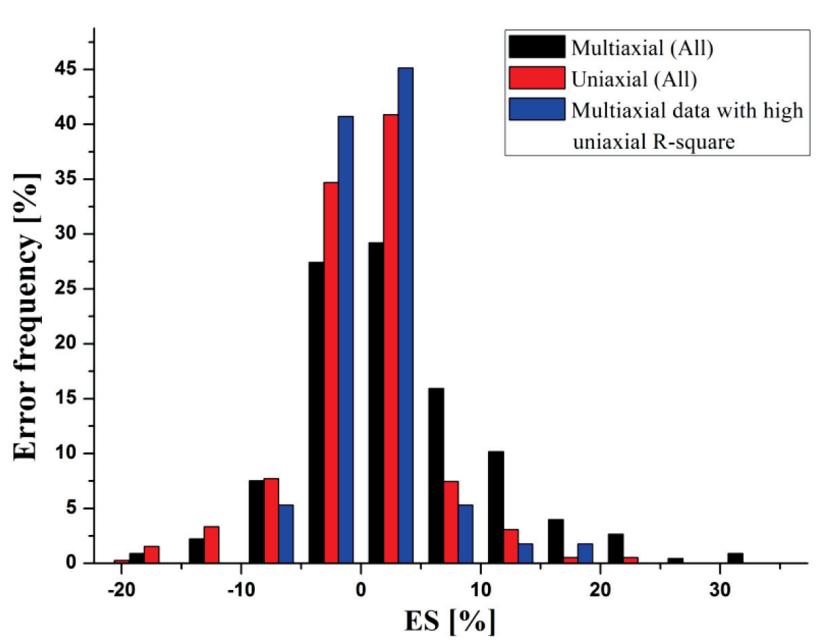

Figure 4: Comparisons of the error frequency of the predicted multiaxial data and the uniaxial data related to all the selected materials and those with a high uniaxial R-square 
Based on the above comparisons, it is reasonable to believe that the hypothesis is correct with a very high probability. Furthermore, it can be concluded that the modified equivalent stress has the ability to represent multi-axial fatigue damage in a finite life interval, and thus the feasibility of the modified method is proved.

Table 1: Materials with a high uniaxial R-square

\begin{tabular}{|c|c|c|c|}
\hline Material & Ref & $\begin{array}{c}\text { Axial } \\
\text { R-square }\end{array}$ & $\begin{array}{c}\text { Torsional } \\
\text { R-square }\end{array}$ \\
\hline Z12CNDV12-2 & {$[7]$} & 0.99 & 0.86 \\
\hline SAE 1045-1 & {$[7]$} & 0.95 & 0.97 \\
\hline SAE 1045-2 & {$[7]$} & 0.97 & 0.95 \\
\hline low carbon steel & {$[7]$} & 0.91 & 0.92 \\
\hline 18G2A & {$[7]$} & 0.93 & 0.88 \\
\hline CK45 & {$[7]$} & 0.91 & 0.95 \\
\hline SM46C & {$[7]$} & 0.96 & 0.88 \\
\hline 30BCD16 & {$[8]$} & 0.99 & 0.99 \\
\hline S355j0 & {$[9]$} & 0.93 & 0.86 \\
\hline
\end{tabular}

\section{RESULTS AND DISCUSSION}

In this section, the validity of the modified method will be examined with 8 sets of metallic materials quoted from the literature, ${ }^{7,8}$ and the original von Mises stressbased method is used for a comparison, as shown in Figure 5. To quantify the accuracy of the present method, a relative error $R e$ is introduced as follows:

$$
\mathrm{Re}=\frac{N_{\mathrm{f}, \text { cal }}-N_{\mathrm{f}, \exp }}{N_{\mathrm{f} \text { exp }}} \cdot 100 \%
$$

Firstly, a round, smooth specimen made of 30BCD16 is taken as an example. ${ }^{8}$ This set of data is accompanied by a high fitting accuracy of both the axial and torsional S-N curves, as listed in Table 1, so it can exclude the impact produced by the dispersion of the uniaxial fatigue curves. As a result, the uniaxial predicted results are in good agreement with the experiment data, as shown in Figure 5a. Meanwhile, it can be seen that the distance between the points representing the multi-axial results of the modified method and the diagonal is closer than that of the original method. In detail, the specific variations of the two multi-axial points in each update step are summarized in Table 2. As can be seen, the convergence results can be obtained after four steps, and the range of the interpolation interval is decreased. As a consequence, the prediction accuracy of each point is improved by about $10 \%$ in terms of $R e$.

As can be seen in Figure 5b, for the material SM45C, the original results are all conservative compared to the experimental data, closed to the scatter band of factor 2. However, the modified predictions are all better than the original ones, included in the factor 2 line. Figure 5c refers to the experimental tests carried out on $\mathrm{AlCu} 4 \mathrm{Mg} 1$ cylindrical specimens. It is clear that the modified method provides more conservative results than original method in the non-conservative region, while results in more non-conservative predictions in the conservative side.

Moreover, it can be seen from Figures $\mathbf{5 c}$ to $\mathbf{5 h}$ that the prediction precision of some of the modified results is worse than that of the original results, such as Figure 5e on material $18 \mathrm{G} 2 \mathrm{~A}$. The above situation could be explained by the fact that, the proposed modified method is based on the hypothesis mentioned in Subsection 2.3, but indeed some experimental samples cannot satisfy the hypothesis perfectly. However, the data in this part has a very small probability, as verified in Section 2.3. In addition, as shown in Figure 5c, this part of the results was originally accompanied by a high prediction accuracy, and the modified results in this part still have high precision. Meanwhile, from Figures $\mathbf{5 c}$ to $\mathbf{5 h}$, it can be observed that the reduction of the prediction accuracy is far less than the improvement in both quantity and degree. As a whole, the predictions estimated by the modified method are seen to be less scattered than those provided by the original method.

To quantify the optimization degree of the new method, an arithmetic error index $d N$ and an increased percentage parameter $E N$ of the fatigue lives are defined as follows:

$$
\mathrm{d} N=\frac{\sum\left|N_{\mathrm{cal}}-N_{\exp }\right|}{n}
$$

Table 2: Each update step of the modified results related to 30BCD16

\begin{tabular}{|l|c|c|c|c|c|c|c|}
\hline \multicolumn{1}{|c|}{$30 \mathrm{BCD} 16$} & $\sigma_{\mathrm{xx}, \mathrm{a}}(\mathrm{Mpa})$ & $\tau_{\mathrm{xy}, \mathrm{a}}(\mathrm{Mpa})$ & $N_{\mathrm{f}, \mathrm{exp}}(\mathrm{cycles})$ & $\lambda$ & $\begin{array}{c}N_{\mathrm{f}, \mathrm{cal}} \\
(\mathrm{cycles})\end{array}$ & $\begin{array}{c}\text { Relate error } \\
(\%)\end{array}$ & $\begin{array}{c}\text { Interpolation } \\
\text { interval (Mpa) }\end{array}$ \\
\hline \multirow{2}{*}{ Original results } & 600 & 335 & 100000 & & 64145 & -35.85 & 86.27 \\
\cline { 2 - 8 } & 548 & 306 & 200000 & & 153006 & -23.49 & 62.98 \\
\hline \multirow{2}{*}{ First iteration } & 600 & 335 & 100000 & 0.90 & 74153 & -25.84 & 3.13 \\
\cline { 2 - 8 } & 548 & 306 & 200000 & 0.92 & 171284 & -13.85 & 2.38 \\
\hline \multirow{2}{*}{ Second iteration } & 600 & 335 & 100000 & 0.91 & 75715 & -24.28 & $1.06 \mathrm{E}-01$ \\
\cline { 2 - 8 } & 548 & 306 & 200000 & 0.92 & 175394 & -12.30 & $8.53 \mathrm{E}-02$ \\
\hline \multirow{2}{*}{ Third iteration } & 600 & 335 & 100000 & 0.91 & 75729 & -24.27 & $3.57 \mathrm{E}-03$ \\
\cline { 2 - 8 } & 548 & 306 & 200000 & 0.93 & 175425 & -12.28 & $3.07 \mathrm{E}-03$ \\
\hline \multirow{2}{*}{ Fourth iteration } & 600 & 335 & 100000 & 0.91 & 75729 & -24.27 & $1.21 \mathrm{E}-04$ \\
\cline { 2 - 8 } & 548 & 306 & 200000 & 0.93 & 175425 & -12.28 & $1.10 \mathrm{E}-04$ \\
\hline
\end{tabular}


B. LIU, X. YAN: A MODIFIED METHOD OF VON MISES STRESS-BASED MWCM FOR FATIGUE-LIFE ...
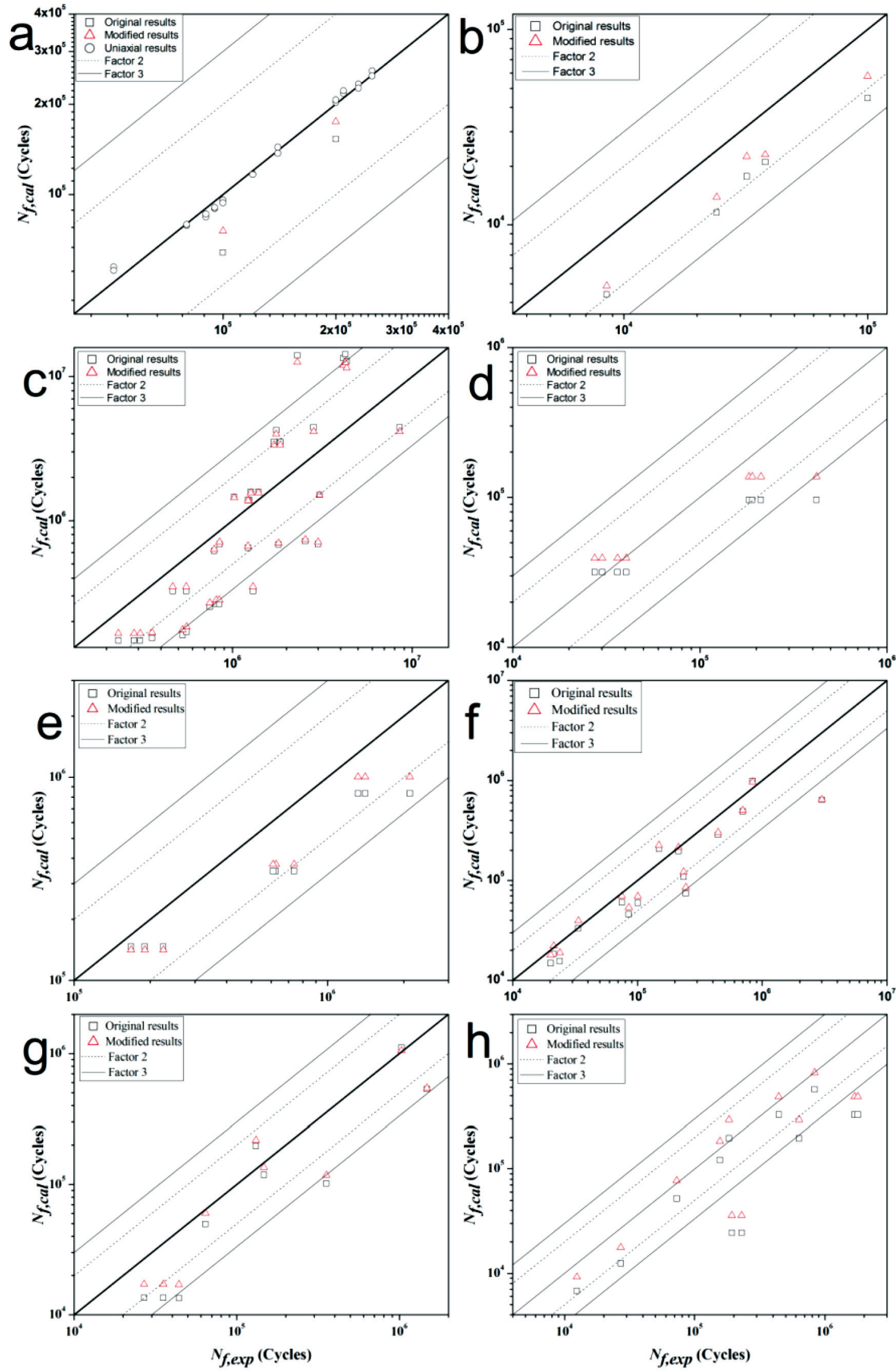

Figure 5: Comparisons of original results and modified results: a) 30BCD16, b) SM45C, c) AlCu4Mg1, d) CK45, e) 18G2A, f) low-carbon steel1, g) low-carbon steel2, h) C40 steel 


$$
E N=\frac{\mathrm{d} N_{\text {mod }}-\mathrm{d} N_{\text {orig }}}{\mathrm{d} N_{\text {orig }}} \cdot 100 \%
$$

where $n$ is the number of multi-axial points of the predicted material. The calculated results are listed in Table 3. It can be determined that the $d N$ representing the deviation between the experimental lives and the predicted lives of the modified method is less than that of the original method, and the increased percentage parameter $E N$ falls within the interval from $3.74 \%$ to $41.04 \%$. Therefore, it can be concluded that as a whole the proposed modified method can improve the prediction accuracy with a certain degree.

Table 3: Values of the arithmetic error index dN and increased percentage parameter EN.

\begin{tabular}{|c|c|c|c|c|}
\hline Material & Ref & $\begin{array}{c}\text { dNorig } \\
\text { (cycles) }\end{array}$ & $\begin{array}{c}\text { dNmod } \\
\text { (cycles) }\end{array}$ & EN (\%) \\
\hline 30BCD16 & {$[8]$} & 41424 & 24423 & -41.04 \\
\hline SM46C & {$[7]$} & 20693 & 16181 & -21.80 \\
\hline AlCu4Mg1 & {$[7]$} & 1948751 & 1738228 & -10.80 \\
\hline low carbon steel1 & {$[7]$} & 225591 & 217157 & -3.74 \\
\hline low carbon steel2 & {$[7]$} & 161655 & 148987 & -7.84 \\
\hline C40 steel & {$[7]$} & 342896 & 285802 & -16.65 \\
\hline 18G2A & {$[7]$} & 317317 & 225945 & -28.80 \\
\hline CK45 & {$[7]$} & 80027 & 59974 & -25.06 \\
\hline
\end{tabular}

\section{CONCLUSION}

The fully reversed, axial-torsional proportional load is the most basic multi-axial loading condition. It can reflect the multi-axial effect purely and is the calibration basis for other fatigue-influencing factors (mean stress, non proportional, etc.). As to this type loading, a modified method from the von Mises stress-based MWCM is first proposed in this paper. The main conclusions are as follows:

- According to the definition of the MWCM, this kind of method is essentially dependent on the interpolation method in terms of the multi-axial parameter $\rho$, and thus the parameter $\rho$ is an obvious influence on factors on the multi-axial life-prediction accuracy.

- To reduce the relative error produced by the deviation of $\rho$, the proposed modified method introduces a ratio parameter $\lambda$ to turn the von Mises stress into a new equivalent stress, so that the interpolation interval near the evaluated point can be decreased.

- To obtain a more accurate value of $\lambda$, the iterative measure is adopted. By this means, the prediction results can be updated according to a proposed criterion until a convergent result is obtained.

- The new proposed method is examined with a large quantity of data from the literature. It can be found that overall the prediction accuracy of the modified results has a certain degree of improvement compared to the original von Mises method.

- Generally speaking, from the point of view of engineering, the proposed approach can be demonstrated as being a suitable method for durability analyses with a high computational efficiency and accuracy.

\section{REFERENCES}

${ }^{1}$ L. Susmel, P. Lazzarin, A bi-parametric Wöhler curve for high cycle multiaxial fatigue assessment, Fatigue Fract Eng M, 25 (2002) 1, 63-78, doi:10.1046/j.1460-2695.2002.00462.x

${ }^{2}$ A. Cristofori, L. Susmel, R. Tovo, A stress invariant based criterion to estimate fatigue damage under multiaxial loading, Int J Fatigue, 9 (2008) 30, 1646-1658, doi:10.1016/j.ijfatigue.2007.11.006

${ }^{3}$ J. Ge, Y. Sun, S. Zhou, Fatigue life estimation under multiaxial random loading by means of the equivalent Lemaitre stress and multiaxial S-N curve methods, Int J Fatigue, 79 (2015), 65-74, doi:10.1016/j.ijfatigue.2015.04.022

${ }^{4}$ I. V. Papadopoulos, P. Davoli, C. Gorla, Filippini M, A. Bernasconi, A comparative study of multiaxial high-cycle fatigue criteria for metals, Int J Fatigue 19 (1997), 219-35, doi:10.1016/S01421123(96)00064-3

${ }^{5}$ M. A. Meggiolaro, J. T. P. D. Castro, An improved multiaxial rainflow algorithm for non-proportional stress or strain histories - Part I: Enclosing surface methods, Int J Fatigue, 42 (2012) 4, 217-226, doi:10.1016/j.ijfatigue.2011.10.014

${ }^{6}$ H. J. Gough, Engineering steels under combined cyclic and static stresses. P I Mech Eng., 160 (1949), 417-440, doi:10.1243/PIME_ PROC_1949_160_040_02

${ }^{7}$ L. Susmel, Multiaxial notch fatigue, from nominal to stress/strain quantities, Woodhead Publishing Limited, 2009, CRC Press

${ }^{8}$ C. Froustey, S. Lasserre, Multiaxial fatigue endurance of 30NCD16 steel, Int J Fatigue, 11 (1989) 3, 169-175, doi:10.1016/0142-1123 (89)90436-2

${ }^{9}$ G. Gasiak, R. Pawliczek, Application of an energy model for fatigue life prediction of construction steels under bending, torsion and synchronous bending and torsion, Int J Fatigue, 25 (2003) 12, 1339-1346, doi:10.1016/S0142-1123(03)00055-0 